\title{
The association between monosymptomatic enuresis and allergic diseases in children
}

\author{
Suzan Yılmaz-Durmuş ${ }^{1}$, Demet Alaygut ${ }^{2}$, Alper Soylu $^{3}$, Caner Alparslan² ${ }^{2}$ Seda Şirin Köse ${ }^{4}$, \\ Özden Anal ${ }^{4}$ \\ Departments of ${ }^{1}$ Pediatrics, ${ }^{3}$ Pediatric Nephrology and ${ }^{4}$ Allergy and Immunology, Dokuz Eylul University Faculty of \\ Medicine; ${ }^{2}$ Department of Pediatric Nephrology, Tepecik Training and Research Hospital, Izmir, Turkey. \\ E-mail: alaygutdemet@gmail.com \\ Received: 14th August 2017, Revised: 9th October 2017, Accepted: 27th November 2017
}

SUMMARY: Yılmaz-Durmuş S, Alaygut D, Soylu A, Alparslan C, Köse SŞ, Anal Ö. The association between monosymptomatic enuresis and allergic diseases in children. Turk J Pediatr 2018; 60: 415-420.

This clinical study was designed to evaluate correlation between monosymptomatic enuresis (MSE) and allergic diseases (asthma, allergic rhinitis, eczema, and food allergy) in pediatric patients.

The study was conducted on 50 pediatric patients with a MSE clinic who were $\geq 7$ years old and applied to two tertiary health institutions between November 2015 and June 2016. Fifty healthy children of similar age, who applied to pediatric outpatient clinics for various reasons, were included as the control group. A questionnaire questioning the presence of food allergy and enuresis in the family and also including the questions of International Study of Asthma and Allergies in Childhood (ISAAC) was distributed to the parents of the children included in the study.

It was found that $52 \%$ of 100 children participating in the study were boys and $48 \%$ were girls and their mean age was $10.8 \pm 2.8$ years. While allergic diseases accompanied $34 \%$ of the cases with enuresis, this rate was found as $12 \%$ in the control group $(\mathrm{p}<0.01)$. It was determined that the family history in terms of enuresis and atopy was at a higher rate in the study group ( $40 \%$ and $26 \%$, respectively) and at a lower rate in the control group ( $2 \%$ and $6 \%$, respectively) $(\mathrm{p}<0.01)$.

It was observed that allergic diseases were more frequent in the cases with MSE at a statistically significant level compared to the group without enuresis.

Key words: enuresis, children, allergic diseases.

Incontinence, also defined as involuntary leakage of urine, is the second most frequent problem of childhood after allergic diseases. ${ }^{1}$ Incontinence can be continuous or intermittent. According to DSM V and ICD 10 criteria, nocturnal incontinence occurring at least once or more a month and for at least three consecutive months at the age of 5 years and over is defined as enuresis. ${ }^{2}$ This situation is called primary enuresis if there is no dryness period, and is called nonmonosymptomatic primary enuresis if daytime urination symptoms and lower urinary tract symptoms accompany. ${ }^{2}$
Allergy can simply be defined as "a negative reaction caused by a substance, which is not harmful for most of the people, in some people".,4 Numerous environmental factors and mutual interaction of a complex gene group take place in the development of allergic diseases in particularly asthma, allergic rhinitis and atopic dermatitis and also atopic diseases such as food allergies, anaphylaxis, urticarial angioedema, and drug allergies develop. Significant data have been obtained through the International Study of Asthma and Allergies in Childhood (ISAAC) study regarding the asthma prevalence

The manuscript was accepted as a poster presentation at the 50th Anniversary Meeting of ESPN, 7-9 September 2018, Glasgow, Scotland. 
throughout the world and Phase 1 studies have enabled comparison of the prevalence obtained from many countries in the world. In Phase 2, possible etiological factors have been emphasized. ${ }^{5}$

Among the reasons of monosymptomatic enuresis (MSE); factors such as genetic factors, maturation delay, impaired awakening mechanism, detrusor hyperactivity, small bladder capacity, and abnormal secretion of antidiuretic hormone have been emphasized. ${ }^{6}$ In addition, it is thought that atopy may have an effect on enuresis. This study was prepared in light of this information and the correlation between MSE and allergic disease was investigated.

\section{Material and Methods}

\section{Selection of study and control groups}

This prospective study was conducted with patients who applied to pediatric nephrology clinics of two tertiary health institutions between November 2015 and June 2016 due to MSE. The research was reviewed and approved by institutional review board and was approved with the report number 2015/26-16. Informed consent form was received from all participants. ISAAC II questionnaire on allergic rhinitis, asthma, and eczema and also the questionnaire on food allergy were applied to the parents of $\geq 7$ year-old children with MSE.

In the study, 65 cases, who were older than 5 years, had complaints occurring at least once or more episodes in a month and ongoing for three consecutive months, had a normal physical examination, did not have urination symptom and lower urinary tract symptoms, did not have systemic disease and history of drug use were included. The cases, who were younger than 5 years old, had a known allergic disease, history of immunosuppressive drug usage, and enuresis due to anatomic and organic reasons, were excluded from the study. 50 patients, who were in similar age group and had no systemic and chronic diseases, were included as the control group. Nine of a total of 65 questionnaires applied were excluded due to insufficient data and 6 were excluded due to the presence of comorbid urinary system pathology. As a result, the study was conducted with a total of 100 patients as 50 cases and 50 controls.

\section{Identification of the questionnaire and data}

The questionnaire had two sections. First section included the general information regarding the children and their family such as: age, gender, medical history, hospitalization history, pregnancy and birth history, birth weight, feeding history in infancy, breastfeeding and/or infant formula intake history, time of transition to solid foods, family history (presence of atopy in the family), another part questioned the presence of food allergies (allergic reaction, which foods cause allergy such as hazelnut, peanut, milk, egg, fish etc.), the presence of a reaction developed by food (pruritus in the body, swelling around the lips or eyes, bulging in the body, redness, abdominal pain, diarrhea etc.), topical or systemic treatment history, and the tests used in the determination of allergies. In the second section, ISAAC Phase 2 questionnaires, whose international validity has been proven and which are used to examine the prevalence and possible etiology of asthma, allergic rhinitis and eczema in different geographical regions, were used. According to the ISAAC questionnaire; the cases who identify the presence of wheezing for the lifetime or for last 12 months, dry cough at nights that is not related to upper respiratory tract infection, exercise-related wheezing in the last 12 months and recurrent wheezing in the last 12 months were identified as having asthma. Other atopic diseases were classified according to the answers of the cases given to the ISAAC questionnaire questions as follows: the cases identifying sneezing, nasal discharge or nasal obstruction which are not related to upper respiratory tract infection, were diagnosed with allergic rhinitis (AR), the cases with itchy-wet eyes accompanying allergic nasal symptoms were diagnosed with allergic rhinoconjunctivitis (ARC) and the cases identifying temporary itchy, red rash in their bodies were diagnosed with atopic dermatitis (AD). The symptoms of the patients were examined in terms of whether they were perennial or seasonal. The presence of history of AR, asthma and eczema in the family was accepted as the presence of atopy in the family.

\section{Statistical analysis}

The study was conducted by using SPSS version 15 software. Compatibility of the variables to 
Table I. Demographic Features of the Patients.

\begin{tabular}{llll}
\hline & Group 1 & Group 2 & $\mathrm{P}$ \\
\hline Gender & 20 female $(40 \%)$ & 28 female $(56 \%)$ & 0.409 \\
Age (year) & $10.5 \pm 2.8$ & $11.1 \pm 2.8$ & 0.260 \\
Accompanying disease & $12(24 \%)$ & $3(6 \%)$ & $<0.001$ \\
Hospitalization history & $19(38 \%)$ & $5(10 \%)$ & $<0.001$ \\
Birth weight (g) & $3370 \pm 639$ & $3353 \pm 436$ & 0.875 \\
Mother milk time & $12 \pm 9.9$ & $9 \pm 6.8$ & 0.186 \\
(month) & $2.3 \pm 4.05$ & $1.7 \pm 3.14$ & 0.426 \\
Usage of formula & $4.9 \pm \pm 1.63$ & & $<0.001$ \\
Weaning time (month) & $5.92 \pm 0.8$ & \\
\hline
\end{tabular}

normal distribution was examined by using visual (Histogram) and analytical methods (Kolmogorov-Smirnov/ Shapiro-Wilk tests). For descriptive numerical variables, mean and standard deviation were used and frequency and percentage distributions were given for categorical variables. While comparison of numerical variables with dependent variable was assessed by using the "t test", the comparison of categorical variables with dependent variable was assessed by using "chi-square test". The situations with the $\mathrm{P}$ value under 0.05 were accepted as statistically significant.

\section{Results}

One hundred patients were included in the study. Of 50 children in Group 1; 20 (40\%) were girls, $30(60 \%)$ were boys; in Group 2, $28(56 \%)$ were girls and $22(44 \%)$ were boys. There was no statistically significant difference between two groups in terms of gender distribution $(\mathrm{p}=0.109)$. The mean age was $10.5 \pm 2.8$ years and was $11.1 \pm 2.8$ years in Group 2. When the accompanying medical problems were examined, 12 (24\%) in Group 1 had an accompanying medical problem; attention deficit and hyperactivity were present in 2 , epilepsy in 2 , simple renal cyst in 1 , chronic immune thrombocytopenia in 1 , thalassemia major in 1 , Celiac disease in 1, familial Mediterranean fever in 1, recurrent headache in 1, hypoplastic left kidney in 1, and intestinal parasitosis in 1. In Group 2; accompanying medical problems were present in $3(6 \%)$ patients. These problems were recorded as nephrolithiasis, anxiety disorder and epilepsy. In terms of hospitalization history; 19 cases (38\%) in group 1 and $5(10 \%)$ cases in group 2 had hospitalization history and this difference was statistically significant $(\mathrm{p}=0.001)$. Table I shows demographic characteristics and additionally, shows mean birth weight, period of breastfeeding, the use of formula, and months of transition to solid foods. In Group 1 the transition time to solid foods was earlier, this was statistically significant $(\mathrm{p}<0.001)$. When the atopy and allergic disorders were examined, it was found that atopy history in family, enuresis history, and chronic disease history were statistically significantly more prevalent in Group 1 but asthma, allergic rhinitis, eczema, food and drug allergy were not significant between the groups. When allergy history of patient and control groups was questioned, latex allergy history was not found in both groups, however, even though asthma, allergic rhinitis, eczema, urticaria, and food allergy were higher in Group 1 in terms of number, they were not statistically significant (Table II)

There was no statistically significant difference between cases and controls in terms of previous wheezing/respiratory distress, wheezing complaint in the last 12 months, awaking from sleep due to wheezing, having wheezing episodes that disrupt talking, wheezing developing after exercise, development of dry cough at nights independently of infection, frequency of asthma attacks, and receiving active asthma therapy ( $p$ values: $p=0.362$, $\mathrm{p}=0.617, \mathrm{p}=0.617, \mathrm{p}=0,112, \mathrm{p}=0.362, \mathrm{p}=$ 0.617 ; respectively).

When the data related to allergic rhinitis symptoms were evaluated, frequency of sneezing without flu, nasal draining, and nose stuffiness was 5.25 times greater in the case group $(\mathrm{p}=$ 0.020, OR: $5.25,95 \%$ CI: 1.07-25.7). Frequency of sneezing without flu, nasal draining, and 
nose stuffiness within the last 12 months was 9.33 times greater $(p=0.31$, OR: $9.93,95 \%$ CI: 1.12-77.7) in the case group. Frequency of itching and watering in eyes associated with nasal draining in the last 12 months was 5.26 times greater $(\mathrm{p}=0.020$, OR: $5.26,95 \% \mathrm{CI}$ : 1.07-25.7) in the case group.

Eczema symptoms which were itchy rashes lasting for at least 6 months in the past, were observed in 2 patients (4\%) in Group 1. There was no eczema history in the control group. When food allergies were evaluated, 7 (14\%) cases in Group 1 developed symptoms following food intake. For 5 of them the reaction was itching and a rash, whereas 2 had diarrhea. The foods causing the reaction were cow milk for 1 case, egg for 1 case, strawberry and seafood for 1 case, peanut for 1 case, and chocolate for 1 case. The cause of reaction in the control group was peanut and egg.

\section{Discussion}

In this study, patients who applied to two tertiary health institutions in Izmir, which is the $3^{\text {rd }}$ major and seafront city of Turkey, were assessed to evaluate the association of enuresis and allergies.

In previous research performed to evaluate this association; Bray 7,8 , approximately 75 years ago, observed that avoiding food and inhalant allergens in children with asthma caused recovery in both enuresis and in asthma symptoms and thus reported that enuresis could have an allergic origin. Further research showed that due to the smooth muscle structure of the respiratory and gastrointestinal system, allergens may have intensively targeted these systems and the bladder with a smooth muscle structure may be affected similarly. After allergen exposure, it is thought that the capacity of the functional bladder is reduced due to the spasm in the smooth muscle of the bladder and thus enuresis occurs. ${ }^{9}$ In some studies, it was determined that daytime urination frequency increased in atopic enuretic patients as a result of the detrusor hyperactivity (R). ${ }^{10}$ It has also been reported that numerous patients with interstitial cystitis (IC) have an allergic disease. ${ }^{10}$ In a study conducted in the cases with IC in Japan; histamine determination

Table II. Allergy and Atopy Histories of Patients and Families.

\begin{tabular}{lccc}
\hline $\begin{array}{l}\text { History of allergy in } \\
\text { family members }\end{array}$ & Group 1 & Group 2 & P values \\
\hline Atopy & $13(26 \%)$ & $3(6 \%)$ & $<0.005$ \\
Enuresis & $20(40 \%)$ & $1(2 \%)$ & $<0.005$ \\
Asthma & $4(8 \%)$ & $2(4 \%)$ & 0.269 \\
Allergic rhinitis & $5(10 \%)$ & $1(2 \%)$ & 0.112 \\
Eczema & $2(4 \%)$ & 0 & - \\
Food allergy & $1(2 \%)$ & 0 & - \\
Drug allergy & $1(2 \%)$ & 0 & - \\
Chronic diseases & $14(28 \%)$ & $5(10 \%)$ & 0.020 \\
Allergy history in & & $1(2 \%)$ & 0.155 \\
children & $4(8 \%)$ & $1(2 \%)$ & - \\
Asthma & $2(4 \%)$ & 0 & 0.117 \\
Allergic rhinitis & $4(8 \%)$ & $2(4 \%)$ & 0.678 \\
Eczema & $4(8 \%)$ & 0 & - \\
Urticaria & $1(2 \%)$ & $2(4 \%)$ & - \\
Angioedema & $4(8 \%)$ & $1(2 \%)$ & - \\
Food allergy & $1(2 \%)$ & $1(2 \%)$ & - \\
Drug allergy & $1(2 \%)$ & 0 & \\
Venom allergy & 0 & & \\
Latex allergy & & & \\
& & 0.678 & \\
\hline
\end{tabular}


was done in the bladder biopsy samples taken from the patients and as a result, histamine release was observed in $17.7 \%$ of the cases having IC associated with asthma, $8.9 \%$ of the cases with IC and without asthma, and $4.5 \%$ in the control group. It was determined that mast cell number increased in the bladder biopsy sample of 5 among 6 cases having IC associated with asthma. According to this study, it is thought that hypersensitivity may locally or generally occur in the bladder in asthma patients and allergic response may sometimes appear in the bladder or in the respiratory tracts and it is suggested that the hypersensitivity trend of these organs is closely correlated with the parasympathetic innervation pathway. ${ }^{11}$ In a study conducted on one hundred and five enuretic children; it was determined that high fever $(p<0.05)$, urticaria $(p<0.01)$, food allergy $(p<0.01)$, drug allergy $(p<0.01)$, and milk intolerance $(p<0.01)$ were statistically significantly more frequent in enuretic boys. In the same study, it was found that eczema was significantly more frequent in enuretic girls $(p<0.02)$ than the control group 12. In another study, it was determined that eosinophilic cationic protein (ECP) levels in enuretic patients $(\mathrm{p}<0.01)$ was significantly 3-4 times greater than the control group. In the same study; it was observed that only soy bean and hazelnut allergy was more frequent among 10 different food types at a statistically significant level in enuretic patients. According to the result of this study, it was suggested that isoflavones, which were highly present in the urine as a result of eating isoflavone-rich soy bean, affixed on the bladder wall and they both reduced the functional bladder capacity and caused detrusor instability. ${ }^{8}$

Asthma, the most frequently seen chronic disease in childhood, is a primary reason limiting quality of life. Prevalence and morbidity of asthma are a gradually increasing problem because it affects the urban population. Epidemiological studies have shown that there is a rapid increase in the prevalence of atopic diseases such as asthma and allergic rhinitis in both developed and developing countries in the last 30 years despite all the background information and advanced treatment opportunities. ${ }^{13}$ In the ISAAC Phase 1 survey conducted on 25.743 children aged between 6 and 15 years in 14 cities of Turkey in 2004, average asthma prevalence was determined as $13.3 \%$ (8.3\%- $18.3 \%)$. Prevalence of allergic diseases was found above average especially in coastal cities; on the other hand, it was below the average in inlands. ${ }^{14}$ In this study, no difference was found between the groups in terms of asthma symptoms.

The most frequently seen allergic disease in childhood is allergic rhinitis (20-40\%). In the literature, it is reported that allergic rhinitis and asthma can be frequently present together. In studies including primary schoolage children conducted in Turkey using the ISAAC questionnaire method, the rate of allergic rhinitis was found between $8.6 \%$ and $17.6 \% .^{15,16}$

In this study, a significant difference was found between the cases and controls in terms of allergic rhinitis symptoms. In the literature, the relationship of eczema with development and continuation of asthma is reported. ${ }^{17}$ In the ISAAC questionnaire study conducted by Sole et al. ${ }^{17}$, on approximately 80,000 children at 21 centers; it was found that eczema prevalence in age range of 6 and 7 years was $7.3-13.3 \%$, eczema diagnosed by the doctor was $7.9-15.4 \%$ and eczema prevalence in age range of 13 and 14 years was $6.3-11.8 \%$ and eczema diagnosed by the doctor was $2.2-14.2 \%$. In this study, there was no significant difference between the eczema symptoms.

Most studies in the literature were conducted by observing the blood immunoglobulin $\mathrm{E}$ and eosinophilic cationic protein level. In the study of Mungan et al. ${ }^{8}$, it was determined that eosinophilic cationic protein levels were 3-4 times greater in enuresis patient group compared to the control group. A study performed on the children aged between 7 and 16 years, who had treatment-resistant enuresis and were referred to a tertiary clinic, it was determined that the asthma history and approved allergy history were significantly more frequent $(p<0.05)$ than the control group. ${ }^{18}$ In this current study, it was found that allergic rhinitis was statistically significantly higher in cases with MSE than the control group $(p<0.01)$, which was compatible with the literature.

A limitation of the study was its small population and the fact that cases were only selected from a tertiary health institutions. 
This may have had an effect on the results. We concluded that the results could be more valuable if studies are conducted with extended and heterogeneous groups. That being said we believe this study is important because there is a limited number of similar studies in the literature.

Consequently, it is possible to determine with an accurate methodology the correlation between allergic diseases and enuresis. It should be examined their treatment and preventability. This can only be achieved by good patient history and long-term follow-up of the patients.

\section{REFERENCES}

1. Nørgaard JP, van Gool JD, Hjälmås K, Djurhuus JC, Hellström AL. Standardization and definitions in lower urinary tract dysfunction in children. International Children's Continence Society. Br J Urol 1998; 81(Suppl 3): 1-16.

2. Austin PF, Bauer SB, Bower W et al. The standardization of terminology of lower urinary tract function in children and adolescents: update report from the Standardization Committee of the International Children's Continence Society. J Urol 2014; 191: e1863-e1865.

3. Arshad SH, Tariq SM, Matthews S, Hakim E. Sensitization to common allergens and its association with allergic disorders at age 4 years: a whole population birth cohort study. Pediatrics 2001; 108: E33.

4. Wahn U, Lau S, Bergmann R et al. Indoor allergen exposure is a risk factor for sensitization during the first three years of life. J Allergy Clin Immunol 1997; 99(6 Pt 1): 763-769.

5. Worldwide variation in prevalence of symptoms of asthma, allergic rhinoconjunctivitis, and atopic eczema: ISAAC. The International Study of Asthma and Allergies in Childhood (ISAAC) Steering Committee. Lancet 1998; 351: 1225-1232.

6. Elder JS. Voiding dysfunction. Kliegman RM, Behrman RE, Jenson HB, Stanton BF (editors). Nelson Textbook of Pediatrics. (18th ed). Saunders: Elsevier 2007: 22492253.
7. Bray GW. Enuresis of allergic origin. Arch Dis Child 1931; 6: 251-253.

8. Mungan NA, Seckiner I, Yesilli C, Akduman B, Tekin IO. Nocturnal enuresis and allergy. Scand J Urol Nephrol 2005; 39: 237-241.

9. Zaleski A, Shokeir MK, Gerrard JW. Enuresis: familial incidence and relationship to allergic disorders. Can Med Assoc J 1972; 106: 30-31.

10. Yamada T, Murayama T, Mita H, Akiyama K, Taguchi $\mathrm{H}$ Alternate occurrence of allergic disease and an unusual form of interstitial cystitis. Int J Urol 1998; 5: 329-335

11. Yamada T, Murayama T, Mita H, Akiyama K. Bladder hypersensitivity of interstitial cystitis complicated by allergic diseases. Urology 2001; 57(6 Suppl 1): 125.

12. Zaleski A, Shokeir MK, Gerrard JW. Enuresis: familial incidence and relationship to allergic disorders. Can Med Assoc J 1972; 106: 30-31.

13. Jacobson JS, Mellins RB, Garfinkel R, et al. Asthma, body mass, gender, and Hispanic national origin among 517 preschool children in New York City. Allergy 2008; 63: 87-94.

14. Kurt E, Metintas S, Basyigit I, et al; PARFAIT Study of Turkish Thoracic Society Asthma-Allergy Working Group. Prevalence and risk factors of allergies in Turkey: Results of a multicentric cross-sectional study in children. Pediatr Allergy Immunol 2007; 18: 566574.

15. Gradman J, Wolthers OD. Allergic conjunctivitis in children with asthma, rhinitis and eczema in a secondary outpatient clinic. Pediatr Allergy Immunol 2006; 17: 524-526.

16. Demir AU, Karakaya G, Bozkurt B, Sekerel BE, Kalyoncu AF. Asthma and allergic diseases in schoolchildren: third cross-sectional survey in the same primary school in Ankara, Turkey. Pediatr Allergy Immunol 2004; 15: 531-538.

17. Solé D, Camelo-Nunes IC, Wandalsen GF, Mallozi MC, Naspitz CK; Brazilian ISAAC Group. Prevalence of atopic eczema and related symptoms in Brazilian schoolchildren: results from the International Study of Asthma and Allergies in Childhood (ISAAC) phase 3. J Investig Allergol Clin Immunol 2006; 16: 367-376.

18. Rawashdeh YF, Hvistendahl GM, Kamperis K, Hansen MN, Djurhuus JC. Demographic of enuresis patients attending a referral centre. Scand J Urol Nephrol 2002; 36: $348-353$. 